\title{
Un casus de derecho canónico matrimonial en el primer libro del Romanç d'Evast e Blaquerna: una aproximación al texto literario desde el contexto cultural ${ }^{1}$
}

\author{
Joser E. Rubio \\ Universitat de València \\ Jose.E.Rubio@uv.es
}

\begin{abstract}
Resumen: El artículo incide en la importancia de recurrir al estudio del contexto cultural de los textos literarios medievales, a partir de un ejemplo concreto: la interpretación del inicio y del capítulo cuarto de la novela de Ramon Llull Romanç d'Evast e Blaquerna. Se propone una lectura que identifica, en la disputa entre los dos protagonistas del primer libro, un típico casus de derecho canónico matrimonial, lectura contextual que pone de relieve la plena inserción del autor en las coordenadas culturales de su tiempo.
\end{abstract}

Palabras clave: Ramon Llull, derecho canónico, historia cultural.

Resum: L'article incideix en la importància de tenir present el context cultural dels textos literaris medievals, a partir de la interpretación de l'inici i del capítol quart de la novel-la de Ramon Llull Romanç d'Evast e Blaquerna. Proposem una lectura que identifica, en la disputa entre els dos protagonistas del llibre primer, un típic casus de dret canònic matrimonial. Es tracta d'una lectura contextual que posa de relleu la inserción de l'autor en les coordenades culturals del seu temps.

Paraules clau: Ramon Llull, dret canònic, història cultural.

Se suele afirmar que la Edad Media es la época en la que se produce en Europa un fenómeno que podemos comparar al que actualmente denominamos como «globalización». Sería el período histórico más «globalizado» en la historia de Europa, si descontamos el momento actual. De hecho, se considera también que la noción misma de «Europa» como unidad cultural nace en la Edad Media. Y, aunque este tipo de comparaciones suelen ser peligrosas, creo que ésta contiene mucho de verdad.

${ }^{1}$ Este trabajo se inscribe en el proyecto de investigación financiado por el Ministerio de Ciencia e Innovación FI2009-14206: «La cultura literaria medieval y moderna en la tradición manuscrita e impresa (IV)». 
En efecto; hay en el medievo una serie de factores que contribuyen a crear una unidad cultural de fondo muy potente que subyace en las manifestaciones particulares de cada región y les otorga a todas ellas un mismo punto de referencia común: la religión cristiana, la lengua latina como lengua de cultura y de relación internacional, el saber heredado de la escuela romana, etc. Por ello, el estudio de la literatura medieval ha de asumir de alguna manera el reto que implica esta globalización de la cultura del medievo y partir del conocimiento de los factores que la constituyen. Es la aproximación metodológica que propone en su manual de Literatura románica de la Edad Media Alberto Vàrvaro, quien dedica todo un extenso primer capítulo de casi ochenta páginas a lo que llama «nociones preliminares», un buen resumen de los factores de unidad cultural dentro del ámbito románico, y que explican el acercamiento comparativista a los textos literarios que trata en los capítulos siguientes. ${ }^{2}$

En definitiva, lo que encontramos en la mayoría de los romanistas que se dedican a la literatura medieval es una metodología de estudio que considera el contexto cultural como parte integrante del texto o, al menos, como herramienta imprescindible para interpretarlo. Así, por poner un ejemplo, la poesía de Ausiàs March, tan complicada a primera vista, tan críptica en su lenguaje conceptual oscuro, puede interpretarse desde sí misma, si se parte de un presupuesto teórico inmanentista, a través de un análisis estructural. Es un acercamiento al texto literario completamente legítimo, y que puede dar resultados muy interesantes, incluso ingeniosos. Pero tampoco debería agotarse el acceso al texto en este nivel, si lo que queremos es entender todos sus significados. Para ello tenemos que conocer las fuentes, los referentes líricos que configuran el espacio literario del amor cortés desde el siglo XII; y, aún más, como han demostrado diversos estudios, algunos recientes, hay que conocer la ética aristotélica, la lectura que de ella hace Santo Tomás de Aquino, y quizás, según algunos, incluso la obra de Ramon Llull puede iluminar pasajes conceptualmente oscuros de la poesía de Ausiàs March. O sea, que se trata de textos plenamente inmersos en un contexto cultural que hay que conocer para poder saber qué quieren decir. ${ }^{3}$

Esto puede parecer muy obvio, a primera vista, pero no lo es tanto si nos atenemos a la práctica de la enseñanza de la historia de la literatura en las escuelas. Quizás porque se enseña muy poca literatura medieval. La «barrera lingüística» que puede experimentar un estudiante de secundaria ante el Poema del Mio Cid, o ante el Llibre de les bèsties de Llull puede ser una explicación, pero normalmente se salva con ediciones «traducidas» o actualizadas. Pero hay otra barrera comunicativa, más allá de la lengua medieval: es la distancia cultural que separa al joven lector - y no tan joven - del texto medieval. Uno de los retos al que nos enfrentamos los profesores de Universidad ante la llegada de estudian-

2 VÀRVARO, Alberto, Literatura románica de la Edad Media. Estructuras y formas, Barcelona, Ariel, 1983, pp. 7-82.

${ }^{3}$ Un estudio reciente que profundiza en la base filosófica de la poesía marquiana desde la recepción tomista de la ética aristotélica es el de GIRONÉS TRUJILLO, M. Teresa, Ausiàs March: entre el desig i la voluntat. De l'ètica de l'amor a la crisi espiritual. Tesis doctoral leída en la Universitat de València el año 2004. Sobre la —hipotética - influencia de Llull en March, vid. RAMÍREZ I MOLAS, Pere, La poesia d'Ausiàs March, Basilea, 1970. 
tes a la Facultad de Filología es cómo hacerles entender esos textos, cuyo nombre y autores conocen pero que, probablemente, nunca han leído - ni han sentido, en la mayor parte de los casos, el más mínimo interés por hacerlo. Ese «extrañamiento» ante el texto se supera en buena medida cuando se explica el contexto. El término «contexto» aparece en el título del máster: «Literaturas Hispánicas (catalana, gallega, vasca) en el contexto europeo». Esa presencia del concepto da cuenta de la intención del máster de relacionar estas literaturas entre sí y de entroncarlas con el contexto cultural europeo, del que son inseparables. Pero cuando hablamos de la literatura del periodo medieval, el «contexto europeo» es, como he dicho, aún más fundamental si cabe.

Aquí es preciso que la historia de la literatura tome contacto con la historia cultural. En el caso de la literatura medieval, este acercamiento desde la historia cultural es necesario por otro motivo, relacionado con el desconocimiento general sobre los textos al que acabo de hacer referencia: los prejuicios con los que a menudo cargan los estudiantes sobre todo aquello que tenga que ver con lo «medieval». Prejuicios tanto positivos como negativos (a menudo más del segundo tipo que del primero), de los que, por otro lado, no se les puede culpabilizar. Hay que empezar pues con un ejercicio intelectual consistente en hacer patente la imagen (las imágenes), los estereotipos a menudo subconscientes sobre la Edad Media y que forman esa especie de barrera cognitiva que hay que derribar para poder disfrutar de sus textos. Una barrera construida, desgraciadamente, todavía en parte en la escuela, pero reforzada a diario por los medios de comunicación, que usan el término «medieval» como sinónimo de bárbaro, tiránico, atrasado, pretecnológico, etc.

El historiador francés Jacques Heers empieza su libro La invención de la Edad Media, de título significativo, con unas palabras polémicas (en realidad todo el libro tiene un fuerte tono polémico); unas palabras en cierto modo «provocativas», que muestran la necesidad de ese replanteamiento de la imagen de la Edad Media a través del ejercicio intelectual que implica el acercamiento científico, desapasionado, a la cultura del pasado. Es decir: el recurso al estudio cultural aplicado a la historia.

Muy a menudo, nuestras sociedades intelectuales manifiestan ser abiertamente racistas. No en el sentido en que interpretamos ese término generalmente, es decir, no en el sentido de desaprobación o desprecio hacia otras civilizaciones, costumbres o religiones distintas de las nuestras, sino por su asombrosa propensión a juzgar negativamente su pasado. ${ }^{4}$

Este es el primer párrafo del prólogo al libro. Inmediatamente, el autor explica que ese «racismo» (aunque, en realidad, aquí sería más correcto hablar de algo así como «etnocentrismo»), proyectado diacrónicamente hacia el pasado, se aplica sobre todo a la Edad Media. Propone un ejercicio instructivo: recopilar una especie de «florilegio» de barbaridades sobre la Edad Media aparecidas en los medios de comunicación. Yo lo he hecho, y da resultado. También entre los

${ }^{4}$ HEERS, Jacques, La invención de la Edad Media, Barcelona, Crítica, 1995, p. 9. 
estudiantes de la asignatura «Introducción a la cultura medieval» hacemos una pequeña encuesta sobre estereotipos medievales, cuyo resultado es significativo. Por ejemplo: la mayoría (y estamos hablando de licenciados) aún considera que en la Edad Media se creía que la tierra era plana, creencia que no se corregirá hasta la aparición de Cristóbal Colón, figura representativa de una nueva mentalidad abierta al progreso científico. Se sorprenden mucho cuando les explicamos que las fuentes científicas con las que trabajaba Colón eran totalmente medievales, y no de las más «novedosas», a diferencia de los monjes que intentan disuadirlo de que emprenda su viaje, quienes dudan mucho, y con razón, de los cálculos del navegante, que atribuye a la esfera terrestre un diámetro mucho menor del real.

Partiendo pues de una definición de «cultura» en sentido antropológico como el conjunto de creencias, rituales, normas, símbolos, etc. que configuran la cosmovisión de una sociedad, intentamos en la asignatura ofrecer unas mínimas claves de la cultura medieval que puedan ser útiles a la hora de entender los textos literarios; pero que pueden servir igualmente para la lectura de otros textos o productos de la cultura medieval, como el arte. Cuál era la concepción del amor, de las relaciones entre los sexos, del matrimonio en los distintos ámbitos sociales; cuál la cosmovisión científica; cómo la escuela y las nacientes universidades se plantean la herencia del saber pagano en el seno de una sociedad cristiana... Estos son sólo algunos de los temas que tratamos, y que acercan al estudiante a la bibliografía de los historiadores más destacados de la llamada «historia de las mentalidades» como Georges Duby, Jacques Le Goff, JeanClaude Schmitt, Michel Pastoureau, Jean Delumeau, etc., por citar sólo los franceses.

¿Qué valor puede tener el acercamiento interdisciplinar a la historia de la cultura medieval para el estudio de la literatura? De eso pretendo tratar en mi conferencia. Pero en lugar de seguir por la vía teórica (pues creo que el auditorio no necesita una justificación de tipo teórico a esa necesidad de la aproximación interdisciplinar), pondré algún ejemplo práctico extraído de algunas consideraciones que despiertan mi interés recientemente en mis estudios, consideraciones que son meras ideas aún por desarrollar pero que quiero compartir con ustedes.

Tomemos una de las primeras «ficciones literarias» (así llamada, por evitar el término «novela») de la historia de la literatura catalana: el «Romanç d'Evast e Blaquerna» de Ramon Llull. ${ }^{5}$ Se trata de una obra de ficción, efectivamente, en la que el autor expone su ideal de reforma espiritual de la sociedad a través de las «aventuras» del personaje que da nombre a la historia. Blaquerna, al igual que los caballeros de los «roman» del momento, también se lanza en su juventud a errar por los caminos, no en busca de aventuras, sino de un lugar donde retirarse del mundo y dedicarse a la vida contemplativa. Pero en su periplo tiene diversos encuentros que le obligan a desviarse cada vez más de su objetivo y a inmiscuirse en la vida activa adoptando responsabilidades crecientes: será abad de

${ }^{5}$ Este es el título que le han asignado los autores de la reciente edición crítica del texto: SOLER, Albert y SANTANACH, Joan (eds.), RAMON LLULL, Romanç d'Evast e Blaquerna, Palma, Patronat Ramon Llull, 2009 (Nova Edició de les Obres de Ramon Llull —NEORL, VIII). 
un monasterio, obispo e incluso papa de Roma. En cada una de estas etapas sentará las bases de la reforma espiritual y social de acuerdo con la propuesta luliana de retorno a lo que Llull llama la «primera intención», que es aquello que justifica la existencia del ser humano, es decir, recordar, entender y amar a Dios. Finalmente, dimitirá como papa y podrá cumplir su sueño incial, el de dedicarse a la vida contemplativa, estadio superior de la vida de cristiano.

Pero antes de que se nos narren estas «aventuras espirituales» del héroe Blaquerna, la novela comienza con la historia de sus padres, un matrimonio formado por una pareja de personajes también muy interesantes, llamados Evast y Aloma. De esta manera, el libro sigue una estructura prefijada que engloba, de manera ascendente, los «cinc estaments de gents a qui és profitós tenir aquest llibre»: «matrimoni», «religió», «prelatura», «senyoria apostòlica» y en la cima, como hemos dicho, «vida ermitana». ${ }^{6}$ Entre el primero de estos estamentos y los cuatro siguientes hay una clara línea de demarcación, la que separa los laicos de los clérigos, los casados de los continentes; por eso, los personajes que protagonizan el primer libro no se corresponden con el personaje principal del resto de la historia. Esa línea de separación que divide a los individuos de la sociedad cristiana en dos grupos bien definidos es el resultado del trabajo de la Iglesia desde los albores del cristianismo, un esfuerzo que tuvo un momento destacado durante la reforma gregoriana alrededor del año 1000, que asentó el carácter sagrado del ministerio sacerdotal poniendo el énfasis, entre otros puntos, en el celibato eclesiástico como marca distintiva de la superioridad de los clerici frente a los laici.

Pero en la novela de Llull nos encontramos con un hecho que puede parecerle curioso al lector que no conozca suficientemente esta historia de las relaciones entre clérigos y laicos en la Edad Media: Evast y Aloma estan casados; son, por lo tanto, unos laicos que viven en el siglo: son una familia rica, gestores de una gran fortuna, con todas las responsabilidades que eso implica. Pero quieren vivir en el mundo como si estuvieran fuera de él, pretenden vivir su condición de laicos como si fueran religiosos. Pareciera com si quisieran cuadrar el círculo, o romper esa barrera, traspasar esa frontera que los clérigos han levantado laboriosamente para marcar distancias respecto al común de los mortales.

$\mathrm{Y}$ es que el modelo de matrimonio que ofrece Llull en el primer libro del «Blaquerna» no es el de un matrimonio convencional, como uno esperaría al leer el prólogo. Se trata más bien de un modelo especial en lo que tiene de liminar, de fronterizo, de estar «en la cuerda floja», o de querer estar en dos sitios a la vez, con un pie en cada lado de la raya, rompiendo así el equillibrio establecido que proporciona un lugar y unas atribuciones específicas a cada grupo. No lo inventa Llull; tiene sus raíces en los albores mismos del cristianismo, pero se reformula y cobra fuerza a partir de los movimientos de laicos vinculados a nuevas corrientes del siglo XIII como los franciscanos espirituales. Se le conoce como «matrimonio espiritual», lo que ya implica una cierta contradicción en los términos, desde el momento en que el trato directo con lo sagrado, la gestión de lo

${ }^{6}$ Ibid., p. 87 («Del Pròleg»). 
espiritual, se reserva en la sociedad cristiana para los que están al otro lado de la frontera, para los célibes.

$\mathrm{Y}$ es que una de las características de este matrimonio espiritual es que, precisamente, implica el celibato de los contrayentes. Contradicción aún más escandalosa. Dyan Elliot explica muy bien en su libro Spiritual marriage. Sexual abstinence in medieval wedlock en qué consiste esa provocación implícita en el matrimonio espiritual, al que califica como «a place in the middle»:

Spiritual marriage, or total sexual abstinence in wedlock, is somewhat of an anomaly because it occasions a blurring of what were widely perceived as two discrete groups: the continent and the married. From the standpoint of social cohesion, there are very sound reasons for keeping these two categories separate. Since the purpose of marriage was to harness the sex urge, either toward the production of legitimate offspring or, according to Paul's reformulation, as a remedy to sin, the suspension of sexual intercourse removed the institution's very raison d'être and had the potential for disrupting gender roles. For this reason, married individuals who were committed to absolute chastity represent a kind of «fifth column» in the otherwise patriarchal institution of marriage. ${ }^{7}$

La autora incluye el caso de Evast y Aloma, en las páginas 175-176 de su libro, como modelo literario de ese matrimonio espiritual cuya historia dibuja de manera clara a lo largo del mismo. Ciertamente, el matrimonio de los protagonistas del primer libro del Blaquerna se resuelve como un matrimonio espiritual que incluye la cohabitación casta entre sus normas, pero ello ocurre después de plantearse otras alternativas que igualmente ponen en cuestionamiento la separación entre los célibes y los casados, de manera incluso más radical que la fórmula de la cohabitación casta.

Ese límite entre los dos estados, el de casado y el de continente, lo debía de tener el personaje de Evast, el marido, bien claro al inicio de la novela. Ésta comienza, precisamente, con las consideraciones del joven Evast sobre su futuro, en el momento en que debe tomar una decisión trascendental para su vida. Heredero de una fortuna a la muerte de su padre, «cap de llinatge», o sea, primogénito, virtuoso, ornado con buenas costumbres y además cultivado en el saber, llega el momento en que se le abre una encrucijada:

Molt fou Evast cobejat en la ciutat per homes de religió i per alguns altres homes seculars, els quals desitjaven acostar-se-li per via de matrimoni. Mentre que Evast era així requerit a orde pels religiosos i a matrimoni pels homes seculars, considerà una nit en l'orde de religió i en l'orde de matrimoni, i li vingué en voluntat que rebés religió per tal de fugir dels vans delits d'aquest món. Però es recordà de les grans riqueses que son pare li havia deixat i com era en càrrec de mantenir la gran casa i la gran almoina que son pare feia vivint

${ }^{7}$ ELLIOT, Dyan, Spiritual Marriage. Sexual Abstinence in Medieval Wedlock, Princeton, Princeton University Press, 1993, p. 17. 
en aquesta vida present. Per totes aquestes raons i perquè ell era també cap del seu llinatge, s'inclinà a entrar en orde de matrimoni. I es proposà donar bona doctrina i exemple estant en matrimoni a tots aquells que són en orde de matrimoni. I desitjà tenir fills que fossin servents de Déu, als quals ell pogués deixar els seus béns temporals, i que abans de la seva mort servís Déu en algun orde de religió. ${ }^{8}$

Desde el inicio mismo de la novela asistimos a la vacilación de Evast, que sopesa los pros y los contras de cada una de las opciones, claramente delimitadas en este párrafo: o matrimonio, o religión. Si ponemos atención al vocabulario quedará clara esta delimitación: Llull se refiere a ambas opciones como «ordenes». No se trata de un término cualquiera, sino de un concepto que tiene un significado importantísimo en la estructura de la sociedad medieval, e incluso en su cosmovisión. En el momento que nos ocupa, el siglo XIII, la Iglesia insistía desde hacía tiempo en el carácter sagrado, sacramental, del matrimonio, que ya formaba parte plenamente de la lista de los siete sacramentos. Es un orden querido por Dios; por lo tanto, un espacio de salvación, aunque no tan perfecto como el otro orden, el sacerdotal. En la cita de Dyan Elliot queda claro que los motivos por los que uno debe casarse son dos: para cumplir con el mandato de Dios en el Génesis, «crescite et multiplicamini» (Gén. 1, 28), y como remedio contra la concupiscencia, de acuerdo con la formulación paulina «melius est enim nubere, quam uri» (I Co. 7, 9). Es mejor permanecer virgen, pero, ante el peligro de la consupiscencia, es mejor casarse que caer en el pecado.

Volvamos a Evast. En su decisión de optar finalmente por el orden de matrimonio, ¿cuál de estos dos aspectos pesa más? Obviamente parece claro que el primero. No se trata de un personaje inclinado a la lujuria, ni a ningún otro vicio. Es un modelo de virtudes, un modelo de santidad, por lo tanto. Por eso instintivamente, podríamos decir, su primera decisión es entrar en religión, de acuerdo con el modelo tradicional de santidad. Pero en el siglo XIII ya se disponen de otros modelos de santidad abiertos a los laicos. Lo que le lleva finalmente al matrimonio parecen ser consideraciones pragmáticas de tipo social: el ser primogénito y responsable de los bienes de la familia. Gestionarlos implica estar en el mundo hasta el cuello y asumir la responsabilidad de dejarlos intactos, o acrecentados, a la generación siguiente; o sea, tener hijos legítimos. Es el «crescite et multiplicamini», no el «melius nubere quam uri», lo que le lleva a tomar la decisión de casarse.

En el marco estructural de la novela, lo que promete esta página inicial es dibujar, a través del personaje de Evast y de su mujer, un modelo de virtudes para los laicos, para los casados que viven en el mundo: «es proposà donar bona doctrina i exemple estant en matrimoni a tots aquells que són en orde de matrimoni». Pero no es así como irán las cosas exactamente. Fijémonos en la frase final del texto reproducido más arriba: «I desitjà tenir fills que fossin servents de Déu, als quals ell pogués deixar els seus béns temporals, i que abans de la seva mort servís Déu en algun orde de religió». Lo que pretende Evast es dar un rodeo,

\footnotetext{
${ }^{8}$ RAMON LLULL, op. cit., p. 89.
} 
cumplir con sus obligaciones sociales antes de satisfacer su impulso primero, claramente expresado como el principal, el originario, el que surge inmediatamente en su corazón cuando se encuentra ante la encrucijada: «li vingué en voluntat que rebés religió per tal de fugir dels vans delits d'aquest món». El reto estará en cumplir esas obligaciones sociales sin descuidar en nada las espirituales: servir a Dios. Servir a Dios como un rico burgués que gestiona una fortuna. Ese es el reto, otro reto que nos llevaría a otra conferencia y a otro tema igualmente interesante. ${ }^{9}$

Nosotros nos quedamos con el tema del matrimonio, aunque está muy relacionado con el anterior, porque aquí se trata de un matrimonio rico. A Evast le pesa la riqueza, le molesta profundamente el tratar con ella, preferiría liberarse de un golpe de todo. Por eso quiere tener un heredero, para descargar en él ese peso. ¿Pero qué pasa con el «peso» o, por mejor decirlo, con las obligaciones del estado de casado? ¿Qué pasa con el matrimonio? Evast también quiere en un momento dado prescindir de él, entrar en religión. Y eso ya no es tan fácil. Es mucho más fácil donar todas las riquezas a los pobres que abandonar el estado de casado, y Evast experimentará esta regla en sus propias carnes. Porque para tomar la última decisión, la de disolver el matrimonio para entrar en el otro orden, debe contar con otro elemento hasta ahora silenciado: la cónyuge, Aloma.

En efecto: Evast toma como esposa a Aloma, una joven hecha a la medida de su devoción y de la vida virtuosa y modélica que pretende llevar como casado. Durante mucho tiempo vivió el matrimonio sin tener hijos. Aloma está triste por no tener descendencia, pero finalmente Dios recompensa la virtud de la pareja concediéndoles el tan ansiado hijo varón, Blaquerna, al que educarán de manera ejemplar. Una vez culminado el proceso de formación de Blaquerna, llega el momento para Evast de dar el siguiente paso en sus planes. En el capítulo cuarto plantea abiertamente a su mujer la nueva situación. El título de este capítulo lo dice todo: «De la disputa que Evast tingué amb Aloma, que no el volgué deixar entrar en religió». La reacción de la esposa es la esperable si tenemos en cuenta lo que realmente le está poniendo delante el marido: Evast le está pidiendo el divorcio, por lo que Aloma piensa que algo muy malo debe de haber hecho para que su marido la repudie, o bien que ha dejado de amarla:

Senyor — digué Aloma-, les vostres paraules, les he ben enteses i m'heu posat en sospita que vós tingueu contra mi alguna mala voluntat per la qual em voleu deixar. Si us sembla que en alguna cosa he fallit contra vós, us prego que d'altra manera de mi prengueu venjança i que no em desempareu ara quan a la fi dels meus dies més he de menester la vostra ajuda i el vostre govern. ${ }^{10}$

Evast insiste en los motivos de su petición: «Però, perquè nosaltres som a la fi dels nostres dies i perquè l'orde de religió és de major santedat que l'orde en

${ }^{9}$ El de la relación de la espiritualidad franciscana con la riqueza productiva fruto de la actividad mercantil, que no es denostada sino considerada un bien para la res publica cristiana. Vid. TODESCHINI, Giacomo, Richezza francescana. Dalla povertà volontaria alla società di mercato, Boloña, Il Mulino, 2004.

${ }^{10}$ RAMON LLULL, op. cit., p. 100. 
què som i hom ha d'acostar-se a Déu al més que pot, (...) per això us prego (...) que entrem tots dos en vida contemplativa i que deixem la vida activa al nostre fill Blaquerna». ${ }^{11}$ A partir de aquí, todo el capítulo se articula como una «disputatio», de acuerdo con el título, en la que cada uno de los contendientes dialécticos ofrece sus argumentos. El razonamiento que esgrime Aloma en primer lugar es de corte totalmente luliano e impecable desde el punto de vista doctrinal:

Atès que el començament de la nostra unió fou per orde de matrimoni i el començament té sempre relació amb la fi, a saber, que sempre estiguem junts fins a la fi, que la mort ens departeixi, per això sapigueu, senyor, que jo de cap manera no vull ésser contra el començament del primer orde en el qual Déu m'ha posat i en el qual Déu m'ha conservat i m'ha guardat de fer cap falliment contra l'orde (...). De l'orde en què Déu m'ha posat no en sortiria per res; ni vós, amb tots els respectes, no m'heu d'aconsellar que prengui un altre orde al qual no tingui tanta devoció com a l'orde en què estic, car per falta de devoció molts homes i moltes dones menyspreen el seu orde i en surten. ${ }^{12}$

La insistencia de Aloma en el término «orde» pone en evidencia lo que comentábamos anteriormente: por boca del personaje femenino se hace una reivindicación del carácter sagrado e indisoluble del matrimonio, instituido por Dios en el paraíso. Evast opone la superioridad del otro orden, el sacerdotal, al que aspira fervientemente, porque en él estará en contacto directo y cotidiano con el misterio eucarístico («perquè em cal més estimar el meu creador i el meu salvador, i perquè desitjo consagrar i combregar el seu cos gloriós.»). Pero la réplica de su esposa no deja lugar a dudas:

És veritat que en aquest món no hi ha ofici tan noble ni tan profitós com és consagrar i santificar el sant cos de nostre senyor Déu Jesucrist; i encara que sigui cosa tan noble, per això no és lícit que hom arribi a aquell sant misteri sinó de forma ordenada; ni per arribar a aquest orde hom no ha de causar mal ni tribulació a altri, en qui s'engendrés per aquella tribulació ira o ocasió de pecat. ${ }^{13}$

Aloma se niega pues a aceptar la petición del marido. Le propone un acuerdo, una alternativa que pueda satisfacer a ambos en lo que tiene de «tercera vía» o de «a place in the middle», parafraseando a Dyan Elliot: seguir casados pero haciendo penitencia, llevando una vida ascética en común, renunciando al sexo, viviendo en castidad dentro del orden matrimonial.

Evast sigue presionando a su mujer, aún después de la disputa, para doblegar su voluntad. Pero al final ha de ceder. Esta «victoria» de Aloma puede interpretarse desde diferentes puntos de vista, según la lectura que se haga del pasaje de la novela. Se puede ver la acción de una mujer valiente que se rebela contra la autoridad del marido, que le planta cara al señor y se sale con la suya: con todos

\footnotetext{
${ }^{11}$ Ibid., p. 101.

12 Ibid.

${ }^{13}$ Ibid., p. 102.
} 
los matices que sean necesarios añadir a esta consideración, se puede leer el episodio en clave feminista. Sin invalidar en absoluto este tipo de interpretación, una lectura que tenga en cuenta, como he planteado al inicio, las claves culturales contextuales debería de poner en juego elementos como el discurso teológico sobre el matrimonio en el siglo XIII, pero también los datos que aporta el derecho canónico; cuestiones que el lector contemporáneo del Blaquerna debía de tener in mente cuando se encontrara con esta historia de disputa matrimonial, y que nosotros sólo podemos recuperar a través del estudio de la bibliografía histórica. $^{14}$

El capítulo cuarto del Blaquerna se convierte así, de acuerdo con esta propuesta, en un típico «casus» de manual de derecho canónico matrimonial; en la narrativización novelada de un claro ejemplo extraído de la casuística estudiada en las escuelas por los canonistas. ¿Qué ocurre cuando uno de los cónyuges desea hacer voto? El derecho matrimonial estaba claro en la época de Llull: sólo en el caso de un mutuo y libre acuerdo de los dos cónyuges puede disolverse el matrimonio para entrar en el otro orden, el de los clérigos. No es una decisión que se pueda tomar unilateralmente, como bien expone Aloma en su argumentación. Es más: la presión que intenta ejercer Evast sobre la voluntad de su mujer roza lo que sería una actitud pecaminosa. El lector del momento así debía de percibirlo - al menos el lector que tuviera conocimiento de estas materias, claro está.

El canonista San Ramon de Penyafort, en la Summa de matrimonio, expone el caso en estos términos (Título V, «De impedimento voti», 2.)

Quis vovere possit videamus. Et est sciendum, quod quilibet sanae mentis, nisi expresse prohibeatur; quoniam votum lege Sancti Spiritus inspiratur.

Prohibentur autem coniuges votum continentiae emittere, nisi pari consensu et voluntate. $\mathrm{Nec}$ ad religionem alter accedere potest sine consensu alterius; et si alter voverit sine consensu alterius, vel etiam intrat monasterium, revocari potest ab altero coniuge. Quod locum habet post carnalem copulam; nam ante carnalem copulam, licet sit matrimonium per verba de praesenti inter eos contractum, potest alter, altero invito et renitente, intrare religionem, et alter remanens in saeculo contrahere. ${ }^{15}$

Igualmente, Santo Tomás de Aquino (Summa Theologica, Supplementum, q. 61 , a. 1 , «Utrum alter coniugum, etiam post carnalem copulam, possit, altero invito, ad religionem transire»):

${ }^{14}$ Este pasaje del Blaquerna ya fue discutido por Lola Badia desde el punto de vista de la concepción luliana del sexo: BADIA, Lola, «Generació o luxúria. Què diu Ramon Llull sobre el sexe: 1. El marc teòric», Actes de les Jornades Internacional lul-lianes Ramon Llull al s. XXI», Palma, Servei de Publicacions de les Illes Balears, 2005, pp. 13-45 (pp. 34 y 35). Sobre la importancia del derecho canónico en la regulación del matrimonio y de tantos otros aspectos de la vida pública y privada en la Edad Media, vid. BRUNDAGE, James A., Medieval Canon Law, Nueva York, Longman, 1995.

15 S. RAIMUNDUS DE PENNAFORTE, Summa de matrimonio, Roma, Commentarium pro religiosis, 1978 (Universa Bibliotheca Iuris, Volumen I, Tomus C), col. 930. 
Nullus potest facere licite quod est in praeiudicium alterius, sine eius voluntate. Sed votum religionis emissum ab uno coniugum est in praeiudicium alterius: quia unus habet potestatem corporis alterius (I Cor. 7, 4). Ergo unus sine consensu alterius non potest votum religionis emittere.

Respondeo dicendum quod nullus potest facere oblationem Deo de alieno (Is. 61,8). Unde, cum per matrimonium iam consumatum sit corpus viri factum uxoris, non potest sine consensu eius Deo ipsum offerre per continentiae votum. $^{16}$

En ambas citas se pone el énfasis en un punto importante: en este caso se considera indisoluble el matrimonio consumado. Y, efectivamente, el de Evast y Aloma lo es en el momento de la disputa. Hay en la historia otros detalles que claramente remiten, una vez más, a los típicos casos de derecho matrimonial. Si volvemos al inicio de la novela, podemos considerar que Evast emite lo que, en buen derecho canónico, sería un votum simplex, en el momento en el que «li vingué en voluntat que rebés religió per tal de fugir dels vans delits d'aquest món». En la Summa de matrimonio de San Ramon de Penyafort se le define así: «votum simplex est quod simpliciter emittitur, nulla sollemnitate adhibita; ut cum dicit: 'voveo continentiam', 'volo esse monachus', et plus non procedit». Es un voto interior, no manifestado públicamente, a diferencia del votum sollemne: «est quando post votum sollemnitas sequitur». ${ }^{17}$ Evast emite un «voto simple», lo que no impide el matrimonio posterior: «si vero simpliciter vovens contrahat postea per verba de praesenti, tenet matrimonium». ${ }^{18}$

La historia de Evast y Aloma, además de ser un «casus» de manual de derecho canónico, tiene también detrás toda una serie de referentes que podían ser más o menos claros para el receptor contemporáneo habituado a estas historias de matrimonios que hacen voto de castidad, un modelo de relación conyugal espiritualizada que hoy ya no forma parte de nuestro panorama sociológico (al me-

16 S. THOMAS AQUINAS, Summa Theologiae, vol. V, Madrid, B. A. C., 1952, p. 306.

17 S. RAIMUDUS DE PENNAFORTE, op. cit., col. 931.

18 Ibid., col. 934. Los canonistas distinguen entre «verba de futuro» y «verba de praesenti». La primera fórmula se refiere a los esponsales, a la promesa de matrimonio que liga a la pareja antes de contraer públicamente el matrimonio propiamente dicho mediante las «verba de praesenti». El «votum simplex» de Evast no anula pues el matrimonio contraído posteriormente mediante «verba de praesenti»; sólo podría anularlo si no hubiera sido consumado. El caso del marido que decide abandonar a la mujer tras contraer matrimonio público para ingresar en religión planteaba una comprensible incomodidad a los canonistas, por lo que muchos reclamaban que la consumación debería de ser inmediatamente posterior a la boda. Y es que antes de la consumación, aún en el caso de un matrimonio celebrado canónicamente mediante «verba de praesenti», todavía uno de los cónyuges puede disolverlo unilateralmente, pues antes de la cópula carnal entre ellos hay tan sólo un vínculo espiritual, no carnal: el segundo sólo lo disuelve la muerte del cuerpo, el primero la «muerte espiritual» que implica el ingreso en religión. Ahora bien: un matrimonio no consumado durante un largo tiempo es una situación que debería evitarse por lo que tiene de anormal. Hay que recordar, por otra parte, la obligación de otorgar el «debitum» a la que están sometidos los dos cónyuges por igual. Con todo, si después del matrimonio y antes de su consumación uno de los cónyuges piensa que es mejor entrar en religión, hay que darle un tiempo prudencial para que se lo piense. Según Santo Tomás, dos meses son suficientes (Summa Theologiae, Suppl. q. 61, a.2). 
nos en nuestro país; en Estados Unidos, entre ciertos grupos protestantes de ideología ultraconservadora, se está recuperando). Ya hemos dicho que la historia de Evast y Aloma tenía referentes en la realidad social del momento. Pero también en otras historias, las hagiográficas. Las vidas de santos eran divulgadas a través de diversos canales y, especialmente, a través de los sermones de los predicadores. Una de ellas, la vida de San Alejo (St. Aleix), tuvo una amplia difusión en tierras catalanas, y es evidente el paralelismo que guarda con la historia de Evast y de Aloma y de su hijo Blaquerna.

Esta hagiografía está recogida en la Legenda Aurea, pero también la encontramos, por ejemplo, en el Recull d' Eximplis de Arnaldo de Lieja (núm. 530). ${ }^{19}$ Los padres de Alejo, Eufemiano y Aglaes, son dos ricos nobles pertenecientes a la alta sociedad romana. Tienen una vida devota, practican la caridad hacia los pobres. Después de varios años de matrimonio sin descendencia, Dios escucha sus ruegos y nace Alejo. Inmediatamente, los esposos hacen voto de castidad, educan cristianamente al vástago y, llegado el momento, lo casan con una joven. Pero la misma noche de bodas, antes de consumar el matrimonio, Alejo convence a su esposa de la importancia de la virginidad y huye de lecho nupcial para irse lejos a vivir entre los pobres al servicio de Dios. La historia de Blaquerna es totalmente paralela a la de San Alejo: también es un hijo deseado que tarda en llegar, sus padres hacen voto de castidad después de su nacimiento y deciden educarlo para que se haga cargo de los bienes de la familia. Deciden igualmente casarlo con una joven, Natana, y si bien no llegan a producirse los esponsales, en una auténtica «encerrona» conciertan las madres de los jóvenes una cita a solas: la noche de bodas de San Alejo tiene su correspondencia en la novela luliana en el capítulo 6, «De la temptació que Natana féu a Blaquerna», en el que, encerrados en una habitación, el protagonisa masculino convence a su prometida de la superioridad de la vida religiosa antes de despedirse de sus padres y marchar lejos para hacer vida de eremita.

El motivo de los padres de santos que hacen voto de castidad dentro del matrimonio después de tener el hijo se repite en otras hagiografías, como en la de San Nicolás. Encontramos aquí otro modelo o tópico que hunde sus raíces en el Antiguo Testamento: el de la pareja estéril que, tras concebir con ayuda divina, consagra a cambio el hijo a Dios. El don divino de la fertilidad, en este caso, es convenientenmente correspondido con la castidad; pero con la del hijo, no la de los padres. Es la descendencia nacida con ayuda divina la que se consagra a Dios (y en el universo cristiano, por tanto, a la castidad), de acuerdo con este modelo que encontramos en el primer libro de Samuel (cap. 1: el nacimiento de Samuel, hijo de Ana y de Elcaná), y que está presente también en el nacimiento de Isaac (hijo de Sara y de Abraham: Gén. 21, 1-5) y en el de Sansón (Jueces 13). También los apócrifos sobre el nacimiento de María repiten el motivo: en el Liber de nativitate Mariae, que la Edad Media incluyó entre las obras de San Jerónimo y que fue reproducido por Santiago de la Vorágine en la Legenda Aurea, un ángel

${ }^{19}$ VORÁGINE, Santiago de la, La leyenda dorada, vol. I, Madrid, Alianza Editorial, 1982, p. 378 y ss. YSERN LAGARDA, Josep-Antoni (ed.), ARNAU DE LIEJA, Recull d' exemples i miracles ordenat per alfabet, Vol. II, Barcelona, Barcino, 2004, p. 162 y ss. 
anuncia a Joaquín y a Ana, tras veinte años de vida conyugal sin descendencia, que tendrán una hija, María, que será consagrada al Señor. ${ }^{20}$

Tanto la historia de San Alejo y sus padres como la de Blaquerna y Evast y Aloma pueden pues entenderse como las de una pareja estéril que, como éstas de los modelos bíblicos, tiene un hijo por obra del Señor, pero que se resiste a asumir la consecuencia necesaria de ese don divino: el hijo debe consagrarse a Dios. Y así ocurre al final. Hagiografías, motivos folclóricos transmitidos en ocasiones a través de los «exempla» de los predicadores, casos de derecho canónico matrimonial... Elementos del contexto cultural de la época que están detrás de un texto como el inicio del Blaquerna, una novela fundamental dentro de la literatura catalana medieval, un texto fundacional, escrito por un gran narrador, un gran literato como Ramon Llull, y que no puede entenderse en toda su riqueza sin esa referencia al contexto cultural. Por eso, como decía al principio, sólo el «viaje en el tiempo» que implica el estudio de la cultura medieval nos permite encontrarnos con el sentido del texto en todas sus dimensiones. Una guía para ese viaje es lo que pretendemos ofrecer con la asignatura del máster los profesores que nos encargamos de ella, y es de agradecer la buena disposición de la directora, la profesora Júlia Butinyà, y de la UNED a la hora de permitir organizar la materia según las necesidades que, para la consecución de ese objetivo, nos habíamos planteado. Y, por supuesto, también es de agradecer la paciencia que han tenido en escuchar mis reflexiones dispersas.

${ }^{20}$ DE SANTOS OTERO, Aurelio (ed.), Los evangelios apócrifos, Madrid, B. A. C., 1999, p. 237 y ss. 